\title{
Food aid in emergencies: a case for wheat?
}

\author{
Jacqueline Landman \\ Centre for Nutrition and Food Research, Queen Margaret College, Edinburgh EH12 8TS, UK
}

\begin{abstract}
As disasters and conflict increase, a higher proportion of total food aid is given as humanitarian aid. Most food aid is in the form of cereals, primarily wheat. The main donors are the USA and the EU, but there is an increase in the numbers of donors, including non-governmental organizations, buying food rather than using surpluses. Alongside the greater diversity and complexity of food aid, there is more controversy about policy and practice. If disasters are development failures, emergency food aid must be a step in the continuum from relief to rehabilitation. Comparisons of the seventeen countries that were major recipients of food aid (> $10000 \mathrm{t}$ ) in 1997, show diversity in social development, dietary pattern, number of refugees, relative food inadequacy and wasting (i.e. \% standard weight-for-height $>2 \mathrm{SD}$ ). In the absence of information of consistent quality, what influences the scale of emergency aid is unclear and susceptible to politicization, so that need and supply may not be matched. Local considerations seem to be as important as external food aid for the nutrition of the recipients. Challenges for the future include assuring the nutritional quality of rations to solve deficiency problems. The implications for the professional public health nutritionist working on emergency food provision include continuing professional development to enhance the technical expertise necessary to design appropriate feeds or rations. These public health nutritionists, more than others, require a grounding in social science theories that underpin management, ethics of professionalism and the politics of food aid.
\end{abstract}

\section{Emergency food aid: Public health nutrition}

\section{Background}

Food aid for relief and emergency operations is very topical for a number of reasons. In the first instance, emergency food aid is more visible than ever as an issue in the mass media, because the Secretary of State for International Development, Clare Short (1998), criticized the aid agencies for abetting the 'endless cycle' of crisis aid. She objected to the fact that the iconography of women and children desperately malnourished and dying in yet another disaster stigmatized all developing countries. The controversy about short-term emergency relief, as opposed to longer-term development aid, arose in the context of a succession of appeals in the Press. The appeal for the Democratic People's Republic of Korea (DPRK) gave way to an appeal for Afghanistan, to be superseded by an appeal for southern Sudan, launched in the Observer, explicitly despite the Secretary of State. The prospect seems to be for more emergencies, even after 'El Nino', as 'new' wars continue in the geo-political adjustments that have followed the end of the Cold War. Thus, the United Nations Development Programme (1997) stated that there is an alarming increase in disasters and estimated that one in every 200 people in the world is either a displaced person or a refugee, as the numbers of violent conflicts reverse or impede human development. Since 1989, the cost of food aid in man-made disasters has outstripped the cost of aid in natural disasters, even when the drought of 1992 that beset parts of Africa is included (Food and Agriculture Organization, 1996a). At the same time, the target amount of food aid that the World Food Council set in 1974 has not been achieved (Food and Agriculture Organization, 1996a). It seems that aid for Eastern Europe and countries from the former Soviet Union is not additional to, but diverted from, the aid available for developing countries (Benson \& Clay, 1998). There will be a shortfall in the amount of aid available from the USA (Shapouri \& Missiaen, 1995) and elsewhere (United Nations Children's Fund, 1998). Greater competition for less food aid would be a particular worry if the criteria for 
giving food aid were opaque. Thus, it is more important than ever to consider food aid in emergencies.

Media representation of humanitarian aid is counter to the conception to which the international agencies subscribe. This conception is that there should be a continuum between humanitarian relief and development aid, and that access to food is assured as a human right. However, there is controversy about applying this ideology in Africa (de Waal, 1996), and about its practicability in Sudan in particular (Macrae et al. 1997).

\section{Concepts of emergencies and development}

Relief is a short-term response to emergencies, whether man-made conflicts or natural disasters, or complex emergencies that combine both aetiologies. However, the consensus is that 'disasters are unsolved problems of development' (Pratt \& Boyden, 1985; World Health Organization, 1994; Food and Agriculture Organization 1996b; United Nations Development Programme, 1997) for which short-term relief is an inappropriate response. Hence, all agencies should integrate relief, successively, with recovery and rehabilitation, as part of an explicit policy to promote sustainable development, including food and nutrition security (World Health Organization, 1994). Treating health and nutrition as human rights means that the way in which technicians and humanitarians anticipate and plan relief must enable sustainable development; i.e. public health nutrition professionals must function conceptually, if not actually, within the relief-recovery-rehabilitation continuum (Macrae et al. 1997). Commitment to such considerations presupposes that conceptual and ethical clarity informs technical rigour. This is especially difficult, given the perils of politicization (McCord, 1997; Watson, 1998). The present paper will consider the implications of some social issues for professionalism of public health nutritionists who work in this extremely complex field. The paper will set selected recent experiences within a broader context of social science literature on food aid, as well as selected nutrition literature, to amplify recent personal experience.

\section{Why wheat?}

In the present paper, making a case for wheat in emergency food aid is a device used to encapsulate the social symbolism of wheat, for instance as a high-status food. Wheat is an inextricable part of the icon of Western international cuisine (Mennell et al. 1992), the bun for the ubiquitous burger. It is also the key commodity in international food trade, imported when countries seek to diversify their food supply, a concomitant to urbanization and economic development. Wheat is the most important of the cereals, the commodities that form the largest category of food aid. The largest single donor of wheat is the USA (Food and Agriculture Organization, 1996a; World Food Programme/International Food Aid Information System, 1998), the solitary superpower. American and international cuisine are more or less synonymous. Thus, wheat pre-eminently illustrates the dilemmas of food aid as humanitarian relief and as a means to achieve food and nutrition security; via dependency or development, through external trade or internal self-reliant production.

\section{Emergency and other food aid}

Shaw \& Clay (1993) have provided an authoritative account of food aid and there is a large literature about food aid in general. For present purposes, it is necessary to briefly define food aid and to explore qualitative and quantitative trends in emergency food aid.

Emergency food aid is an example of a 'transfer from donor to recipient countries of food commodities on a totally grant basis', not on 'highly concessional terms' (Food and Agriculture Organization, 1996a). Irrespective of source or channel, commodity food aid is distributed directly, by the World Food Programme, for and with other agencies for relief in emergency operations, in protracted refugee and displaced person operations (PRO). In 1997, for the fourth consecutive year, programmed food aid made up less than half global deliveries, confirming a shift away from untargeted food aid (World Food Programme/International Food Aid Information System, 1998).

\section{Recipients and donors of emergency food aid}

In recent years, the number of recipient countries has increased to over 100 countries, about two-thirds of United Nations members, covering all regions. Regionally, relief and project aid went primarily to Sub-Saharan Africa, second to South East Asia, and third to Eastern Europe and countries of the former Soviet Union (World Food Programme/International Food Aid Information System, 1998). The major donors were the USA and the EU. Importantly, the number of donor countries has increased and the source of food has become more variable. In addition to production surpluses, donors may contribute funds for local purchases, or for triangular transactions that involve buying or exchanging food with other developing countries. The USA does not engage in local purchases or triangular transactions (World Food Programme/ International Food Aid Information System, 1998). By comparison with the major donors, non-governmental organizations donate modest amounts of food aid, but being donors at all is a further sign of the diversity of food aid. Diversity is complex, and creates more flexibility; it extends the possibilities of supplying aid to countries that governments will not support on political grounds, and this has implications at operational level.

Historically food aid is a foreign policy instrument for the USA, the largest food aid donor. In order to evaluate US food aid policy empirically, Ball \& Johnson (1996) analysed US food aid to African countries in the 1970s and 1980s. The factors they looked at included: size of US cereal surpluses; voting in the United Nations (as a measure of political influence); infant mortality rate (as a measure of humanitarian need that reflects health and nutritional status). Ball \& Johnson (1996) found that in the 1980s, food aid for famine relief and other assistance (Public Law PL480 Title II) was independently associated with infant mortality rate, but not with political measures. Conversely, in the 1970s, political and agricultural considerations were statistically 
significantly associated with donations of food aid but not infant mortality rate. This is evidence of a welcome shift in policy. However, the USA has not attempted, as have other donors, to uncouple national interest from humanitarian considerations.

The Ball \& Johnson (1996) analysis inspired a comparison of the countries that received large amounts of humanitarian food aid. The purpose of the comparisons was to see whether commonly used indicators of social and economic development, nutritional status and risk, support the view that emergency relief is an unsolved problem of development. If that were the case, the rank order of humanitarian food aid would be related to objective indicators of contemporary need or underlying trends in nutritional status. This approach placed humanitarian relief in emergencies in the context of prospects for world food security. The World Food Summit (Food and Agriculture Organization, 1996c,d) and Sixth World Food Survey (Food and Agriculture Organization, 1996b) articulated an achievable goal of reducing the numbers of malnourished people by half. Emergencies may adversely affect achieving this goal in the next millennium. It would be useful to find indications that the need for emergency food aid is associated with factors that are well accepted as underlying causes of food insecurity and malnutrition.

\section{Comparison of major food aid recipients for 1997}

Seventeen countries were major recipients of relief aid in 1997 (World Food Programme/International Food Aid Information System, 1998), arbitrarily defined as $10000 \mathrm{t}$ or more in cereal equivalent aid. All the countries had experienced emergencies or PRO for at least 3 years between 1993 and 1997. The countries varied in classification of their economic and development status. They included a 'developed transitional' country (former Yugoslavia) and two 'middle-income' countries (DPRK and Iraq) as well as the majority from the categories of 'lowincome food deficit' and 'least-developed' countries (Food and Agriculture Organization, 1996b). These major recipient countries differed in the classifications of their dietary patterns, as devised by the Food and Agriculture Organization (1996b). Each type of dietary pattern is represented among the countries that headed the list for recurring emergency food aid in 1997. In most of the countries the primary staple was as important a source of dietary energy supply in 1990-2 as had been the case in 1969-71 (Food and Agriculture Organization, 1996b). Exceptionally, the contribution that wheat made to the dietary energy supply in Sudan more than doubled (from $7.5 \%$ to $18.4 \%$ ), perhaps reflecting the long-standing importance of food aid (Administrative Committee on Coordination/SubCommittee on Nutrition, 1989). Four 'wheat'- and three 'cassava-(Manihot spp.)'-eating countries were among the major PRO recipient countries.

Two approaches from the Food and Agriculture Organization $(1996 b, c)$ were used to compare the extent of food insecurity in these major recipient countries. The first used 'relative inadequacy of food supplies', which was defined as 'the total energy deficit expressed as a percentage of the dietary energy supply'. 'Relative food inadequacy' in
1990-2 was described as 'critical' in only five countries that were major recipients of relief food aid due to PRO, i.e. Kenya, Afghanistan, Ethiopia, Angola and Liberia. Otherwise, there was no relationship between ranking in 'relative food inadequacy' and ranking according to emergency food aid received in 1997.

Two countries, Afghanistan and Ethiopia, were major recipients and had relative food inadequacy that had been rising, so that further growth in food supply would be essential before redistributive measures could have positive effects (i.e. category 1). Eleven major food aid recipient countries, Angola, Liberia, Kenya, Cambodia, Nepal, Pakistan, Rwanda, Iraq, Tanzania, Sudan and Laos, were in category 2 (i.e. they were defined by the Food and Agriculture Organization $(1996 b, c)$ as countries where food inadequacy had fallen, and redistribution could have a positive effect, provided that food supplies increased). In one major recipient country, Uganda, food inadequacy had fallen by half, so that the primary focus could be on distribution measures (Food and Agriculture Organization, $1996 b, c$; category 3). Only one country, DPRK, had a low relative inadequacy (at or approximately $2.5 \%$ ), meaning that redistribution measures could eliminate food inadequacy (category 4). The Food and Agriculture Organization relied on the individual countries for the quality and quantity of the information used to make these assessments. If the data on which relative food inadequacy was assessed were accurate, the emergency in DPRK was quite unexpected. It is clear that indicators of relative food insecurity in 1990-2 did not predict the scale of humanitarian food aid supplied to the major recipient countries in 1993-7. If underlying food insecurity and indicators of social development level do not predict the occurrence or scale of emergencies, there seems to be a need for other more sensitive indicators. National governments are set to establish and develop information systems to detect food insecurity and vulnerability (Food and Agriculture Organization, 1997). It is unclear how appropriate information can be obtained where there is no national or state authority, or where the jurisdiction of national governments is contested, e.g. in complex emergencies.

It is possible that the need for emergency food aid in 1997 should have been related to numbers of refugees reported in each of the countries and the prevalence of wasting (\% standard weight-for-height <2 SD) at about the same time. The numbers of refugees and displaced persons represent huge requirements for dietary energy supply which would be impossible for low-income food-deficit countries to supply. DPRK was the only major recipient that reported no problem of displaced persons or refugees. Wasting in young children is still the best and most widely available indicator of nutritional need on a public health scale. Nonetheless, limited data restricted the comparison to four countries that were major recipients of emergency food aid. There was very little information available about nutritional status in DPRK, showing that despite an extensive national health service there was no system of national nutritional surveillance. Thus, the limited evidence available came from a cross-sectional survey conducted in 1997 of non-random samples of children under 7 years old measured at forty nurseries and kindergartens (World Food 
Programme, 1997). Estimates of wasting ranged from 0 to $31.7 \%$, with a median of $14 \%$ (World Food Programme, 1997). There was evidence of acute severe protein-energy malnutrition in selected hospitals (World Food Programme, 1997; J. Landman, unpublished results), and that recentlydischarged children remained malnourished in the community (World Food Programme, 1997) and were re-admitted to hospitals (J. Landman, unpublished results). However, the deficit in dietary energy supply had been estimated to be at a 'critical' level. While one could see that many people were thin, as was reported in the Press (Anonymous, $1998 b$ ), there was no objective evidence of an emergency with a risk of up to two million deaths (Anonymous, 1998a). Thus, it remains unclear why, in 1997, DPRK was the biggest recipient of emergency relief and, at that time, the largest in history (World Food Programme/International Food Aid Information System, 1998).

If the median prevalence of wasting in children under 7 years old was actually representative of the nutritional status of the DPRK population, there was more wasting than was reported from Rwanda where estimates also varied with location, e.g. at Goma the estimate was between 1.6 and $3.5 \%$ (Administrative Committee on Coordination/ Sub-Committee on Nutrition, 1997). However, in former Yugoslavia there was less wasting in children than in elderly subjects (Watson \& Vespa, 1995), thus it would be imprudent to assume that the levels of wasting in DPRK children under 7 years of age represent the nutritional status of their communities. Sudan had higher levels of wasting in two locations, consistent with the 'catastrophic' food situation (Administrative Committee on Coordination/ Sub-Committee on Nutrition, 1997), despite the large scale of relief aid. Based on this criterion, the rationale for the scale of food aid to these major recipient countries is unclear, hence concerns about politicization of the humanitarian effort.

There is considerably more information about malnutrition in recipient countries with long-standing PRO. There is evidence that in Afghanistan, Liberia and Nepal wasting has decreased over time, and is lower in settled selfsufficient refugees than among displaced persons (Liberia) or in the general population (Administrative Committee on Coordination/Sub-Committee of Nutrition, 1997). Thus, it is unsurprising that Seaman (1993b) questioned the need for full rations for Afghans. Fluctuations in the prevalence of wasting in other situations must be partly attributable to the nature of some protracted complex emergencies that have poor prognoses for resolution, as renewed conflict in 1998 in Sudan, Ethiopia and former Yugoslavia has shown.

One of the criticisms of emergency food aid is that it arrives too late for the humanitarian need and floods local markets resulting in a collapse in demand for local production. A recent study revealed another aspect of the implications of analysing resale of food aid in context. Dorosh et al. (1995) assessed the impact on a local market in Mozambique. They found that the cross-price elasticity for maize was low. Dorosh et al. (1995) concluded that donated yellow maize had high potential to alleviate poverty, since it was self-targeted, being eaten by the poorest in the population and having limited sales at lower prices than the preferred locally-produced white maize.
A long-standing criticism of food aid is that it encourages changes in food patterns, towards imported food and away from locally-produced foods. Food trade contributes to diversity in the diets of the countries that can afford to import food. It is difficult to disentangle the impact of food aid from other influences, such as economic development and urbanization. Thus, a study by Galanis et al. (1995) in Western Samoa, fortuitously before and after a cyclone, is of particular interest. Galanis et al. (1995) used a fortyitem food-frequency (amount) questionnaire to measure food consumption of adult women and men in rural and urban areas of Western Samoa, 5 months before and 8 months after the relief programme. When the post-cyclone survey was conducted banana and taro (Colocasia esculenta) crops had 'normalized', but not coconut and breadfruit (Artocarpus altilis) crops. Galanis et al. (1995) observed increases in consumption of relief foods (rice, bread and pancakes) and decreases in the consumption of local staples. Pancakes and rice contributed more, while breadfruit and yams (Dioscorea spp.) contributed less, to dietary carbohydrate intake and to total dietary energy intake, especially in the rural areas. Although the study did not measure consumption of food aid items directly, Galanis et al. (1995) concluded that the changes were due to food aid. It is noteworthy that local foods contributed the majority of carbohydrate: $40 \cdot 3$ (SE 1.14) \% in 1991 compared with 30.3 (SE 0.92) \% in 1992, and thus the change in energy contribution (-2.8 (SE 0.98$) \%$ ) was also correspondingly small. Thus, food aid foods made a small contribution to dietary energy (4.6 (SE 0.42) \%). While this study provides empirical evidence that a food aid programme could have a statistically significant effect on food preferences, it could not exclude the possibility that the emergency programme accelerated an existing trend towards imported foods in rural areas. Re-assessing diet when breadfruit and banana supplies have recovered might confirm whether a long-term change has taken place. This study cannot be generalized to countries that received large amounts of humanitarian food aid for a period of years rather than months, and where undernutrition rather than obesity is a problem.

The occurrence of micronutrient deficiencies and the persistence of severe wasting among refugees, and to a lesser extent among displaced persons, raises questions about the quality of relief food, especially when food aid is a mainstay or the only supply, and relief programmes last for years.

One non-nutritional but vitally important problem is whether the donated food commodities are fit for human consumption at the point of purchase, and on arrival in recipient countries, and remain edible in transit and in storage. Moisture content and broken grains were found to be important contributors to the problems of infestation and spoilage in Mozambique, Zambia and Sudan (Walker, 1996). The USA and the EU differ in the levels at which standard specifications for moisture are set, and both permit higher levels of moisture than is acceptable in the tropics. Commissioning and monitoring to ensure quality in such respects pose difficult technical and managerial problems for the local staff, compounded by transport costs and availability and security of storage, which are clearly important for a public health nutritionist to be aware of, but 
outside the scope of the public health nutritionist to deal with directly.

Food aid is of course intended for consumption, not for resale. Food aid that enters the local market could be surplus to recipients' needs, which is a sign that the emergency has been mitigated. However, Reed \& Habicht (1998) found that in Zaire sales of food aid were a sign of nutritional distress, a strategy to improve the acceptability of the ration, and to diversify and hence balance the diet.

Problems of palatability and acceptability of donated foods must be anticipated, given that rations are mainly whole grains or flour (primarily wheat) supplied with pulses, and some other foods, such as oil and sugar (World Food Programme/International Food Aid Information System, 1998). In terms of the value of tonnage, in the USA little food aid is blended and fortified at source. Blended foods were valued in Oxfam's studies in Nepal, Ethiopia and Tanzania (Mears \& Young, 1998). Cereal foods need to be prepared and cooked to be edible and palatable. This requires fuel, utensils, potable water and culinary skills, which may not be available in emergency situations. At the local level, operational problems may be the familiar technical ones that constrain recipe development, e.g. lack of information about food composition and lack of ingredients. In Oxfam's recent case studies, supplying 'improved' or kerosene stoves overcame fuel problems (Mears \& Young, 1998). While it is likely and natural that recipients want familiar foods, they do adapt where the donated cereal-based food can be made into porridges or other acceptable familiar dishes. On a larger scale, productive capacity to mill or blend or fortify cereal-based foods may be limited, inevitably constrained by the state of the infrastructure that may pose operational and logistical problems.

Since Clay (1987) and Seaman $(1987,1993 a)$ spoke to the Nutrition Society about development, food aid and the role of nutritionists, considerably more attention has been focused on nutrition issues in emergency food aid (Shoham, 1992; Administrative Committee on Coordination/SubCommittee of Nutrition, 1993, 1997; Katona-Apte, 1993; Hussain \& Herens, 1997; Muehlhoff \& Herens, 1997). Food aid has been severely criticized as 'too little, too late' as refugees and displaced persons in famine shelters have high mortality rates due to disease, and experience severe protein-energy malnutrition and micronutrient deficiencies, e.g. ascorbic acid and thiamin (Shoham, 1992; Seaman, 1993b; Toole, 1993; Kloos \& Lindtjorn, 1994). Intoxications due to lathyrism, ergotism and other poisons have also been reported in displaced persons in Ethiopia who eat wild gathered foods to stave off famine (Kloos \& Lindtjorn, 1994), contributing to the range of public health problems that affect refugees and displaced persons (Shoham, 1992; Administrative Committee on Coordination/Sub-Committee on Nutrition, 1997; Mears \& Young, 1998). Thus, despite reliance on rations, nutritional status could be better where refugees were self-sufficient, as was found in Rwanda (Kloos \& Lindtjorn, 1994; Administrative Committee on Coordination/Sub-Committee on Nutrition, 1997). The design of the ration, including how much should be distributed relative to recipients' dietary energy and nutrient requirements, could be flawed by technical weaknesses, as pragmatic considerations overwhelm nutritional considerations; e.g. eking out rations in case or because supply is uncertain, operational pragmatic lowering in the threshold criterion for declaring an emergency (Macrae et al. 1997), the distribution of rations at below physiological levels and against explicit policy guidelines, as if the emergency will be brief and reversed completely. The treatment of severe protein-energy malnutrition is well established (Ashworth et al. 1996) and can be implemented effectively in emergency relief operations (Golden \& Briend, 1993). It is possible to reduce the cost of treating severelymalnourished individuals, for example, by using Oral Rehydration Fluid instead of Rehydration Solution for Malnutrition, or mixing milk, sugar and oil instead of using proprietary fortified high-energy milk formulas. However, it is only ethical to make such changes if appropriate trace element, mineral ( $\mathrm{Mg}$ and $\mathrm{K}$ ) and multivitamin preparations are supplied at the same time.

Problems may be due to managerial weaknesses at the operational level, as programme staff may lack accountability. Seaman (1993b) drew attention to the inherent problem that operational staff are accountable to donors not recipients. Thus, donors are more interested in supply of, or access to, food aid rather than the effect of food aid on the dietary intake and nutritional status of the recipients. However, food aid monitors, for example, could assess the impact of food aid on nutritional status as well as whether it is being distributed appropriately. Donors would need to change policy and to act in concert to get the key multilateral agencies to make measures of impact on nutritional status and food security higher priorities.

The problem of operating in emergencies, and especially complex emergencies, cannot be overestimated. Not all unsophisticated protagonists may respond to negotiation (Macrae et al. 1997). Where access to food aid part of war and acceptance of the notion that freedom from famine is a human right so weak, that the moral price for short-term humanitarian aid may be too high (de Waal, 1996). Localized problems can explain the differences and deficiencies in the interpretation of information that should lead to action, i.e. to supply food rations or supplements (Macrae et al. 1997; Administrative Committee on Coordination/Subcommittee on Nutrition, 1997). Detailed nuanced understanding is necessary in special local circumstances in Ethiopia (Pratten, 1997), Kenya (Bush, 1995) and Sudan (Patel, 1997), and in special problems such as gender issues, e.g. in Uganda (Payne, 1998). Understanding political context is essential to enable the technician to work out ethical stances clearly enough to anticipate and limit the extent to which nutritional expertise or humanitarian effort is completely co-opted, at worst, or manipulated to serve geo-political ends. The case of DPRK is salutary; while representative surveys that could provide objective estimates of nutritional status cannot be undertaken, commentators have linked the purported 'famine' and emergency relief programme to the peace talks (Holloway, 1997; Islam, 1998). Food aid may be an instrument of foreign policy, a means to influence countries that have no other dealings with the West or the USA. Technical advice, no matter how disinterested, is rooted within Western 
scientific and professional cultures and personnel, whether representing donors, recipients, or non-governmental organization humanitarian agencies, and consequently may have conflicting political interests. Technical questions could be resolved if staff, consultants and volunteers working with relief aid programmes were well trained or had good back-up from qualified and experienced staff who could foster continuing professional development and facilitate reflective practice, the hallmarks of contemporary professionalism.

\section{Conclusions}

The present paper has shown that food aid in general is changing, and that emergency aid is under scrutiny in terms of impact on the most vulnerable people, the displaced, refugees and others stricken by disasters. Selected major recipient countries have varied greatly in level of social and economic development, dietary patterns, relative food inadequacy, numbers of refugees or prevalence of wasting. The largest-scale humanitarian efforts have involved complex situations, a trend that is expected to continue and that may hamper global efforts to reduce malnutrition and increase food security.

Waterlow $(1987 a, b)$ noted that political action is necessary to solve the underlying cause of malnutrition. Political action is essential to make peace that is prerequisite for preventing or resolving complex emergency situations. Peacemaking is not in the hands of public health nutritionists. However, as democracy goes hand in hand with the human right to be free from famine, politicization of public health nutrition at an operational level is probably inevitable. This politicization does not mean that nutrition will be even more marginalized now than when Seaman (1993a) delivered his lecture, because of professionalization in public health nutrition. Public health nutritionists are required to be competent in social aspects of the theory and practice of nutrition. Most relevant is competence in 'developments in the sociology and politics of institutions, stakeholders, agents and agencies in national and global food and public health systems, sustainability and equity in public health nutrition programmes' (The Nutrition Society, 1997). This inter-disciplinary knowledge underpins the skills of inter-professional and team working, management and advocacy (The Nutrition Society, 1997; Landman et al. 1998). Those who work in emergencies also need political acumen to be able to function professionally. This requirement suggests that registered public health nutritionists would not be on the margins of debates about food aid in emergencies and for development. Registered public health nutritionists would be able to articulate and advocate their technical positions within real world contexts and would be reflective practitioners. Such professionals would recognize the particular and specific issues, problems and resources that characterize localities with emergencies, and would know how to gauge the prospects for recovery and rehabilitation or development towards sustainability. This responsibility is the more appropriate and greater challenge than making a case for wheat or any other food.

\section{Update}

The Overseas Development Institute, has launched a review of the Department for International Development's humanitarian food aid policy, which could have major repercussions for UK policy and for the UK's relationship with the World Food Programme and other agencies. The ways in which the humanitarian issues relate to food and nutritional issues may be expected to profoundly alter British food aid in the next millennium.

\section{References}

Administrative Committee on Coordination/Sub-Committee on Nutrition (1989) Update on the Nutrition Situation. Recent Trends in 33 Countries. Geneva: ACC/SCN.

Administrative Committee on Coordination/Sub-Committee on Nutrition (1993) Nutritional Issues in Food Aid. Symposium Report Nutrition Policy Discussion Paper no. 12. Geneva: $\mathrm{ACC} / \mathrm{SCN}$.

Administrative Committee on Coordination/Sub-Committee on Nutrition (1997) Third Report on the World Nutrition Situation. Geneva: ACC/SCN.

Anonymous (1998a) Guardian 14 March issue, p. 1.

Anonymous (1998b) Guardian 15 April issue, p. 15.

Ashworth A, Jackson A, Khanum S \& Schofield C (1996) Ten steps to recovery. Child Health Dialogue 3 and $\mathbf{4}, 10-11$.

Ball R \& Johnson C (1996) Political, economic and humanitarian motivations for PL480 food aid: evidence from Africa. Economic, Development and Cultural Change 44, 515-537.

Benson C \& Clay E (1998) Additionality or diversion? Food aid to Eastern Europe and the former Soviet Republics and the implications for developing countries. World Development 26, 31-44.

Bush J (1995) The role of food aid in drought and recovery: Oxfam's North Turkana - (Kenya) drought relief programme, 1992-94. Disasters 19, 245-259.

Clay E (1987) European food aid as a tool for relief and development in Sub-Saharan Africa. Proceedings of the Nutrition Society 46, 281-300.

de Waal A (1996) Social contract and deterring famine: First thoughts. Disasters 20, 194-205.

Dorosh P, del Ninno C \& Sahn D (1995) Poverty alleviation in Mozambique: a multi-market analysis of the role of food aid. Agricultural Economics 13, 89-99.

Food and Agriculture Organization (1996a) Food Aid in Figures, 1994, vol. 12. Rome: FAO.

Food and Agriculture Organization (1996b) The Sixth World Food Survey. Rome: FAO.

Food and Agriculture Organization (1996c) World Food Summit. Technical Background Documents 1-5, vol. 1. Rome: FAO.

Food and Agriculture Organization (1996d) World Food Summit. Technical Background Documents 12-15, vol. 3. Rome: FAO.

Food and Agriculture Organization (1997) State of Food and Agriculture, 1997. Rome: FAO.

Galanis D, Chin-Hong P, McGarvey S, Messer E \& Parkinson D (1995) Dietary changes associated with post-cyclone food aid in Western Samoa. Ecology of Food and Nutrition 34, 137-147.

Golden MHN \& Briend A (1993) Treatment of malnutrition in refugee camps. Lancet 342, 360.

Holloway N (1997) Politics of famine. Far Eastern Economic Review 1 May issue, 14-16.

Hussain A \& Herens M (1997) Child nutrition and food security during armed conflicts. Food Nutrition and Agriculture 19, $17-24$. 
Islam S (1997) Strategic largesse EU's food aid to North Korea has broader political implications. Far Eastern Economic Review 5 June issue, 21.

Katona-Apte J (1993) Issues in food aid and nutrition. Nutritional Issues in Food Aid. Nutrition Policy Discussion Paper no. 13, pp. 5-20. Geneva: ACC/SCN.

Kloos H \& Lindtjorn B (1994) Malnutrition and mortality during recent famines in Ethiopia: implications for food aid and rehabilitation. Disasters 18, 130-139.

Landman J, Buttriss J \& Margetts B (1998) Curriculum design for professional development in public health nutrition in Britain. Public Health Nutrition 1, 69-74.

McCord A (1997) Democratic Peoples' Republic of Korea. Research Practice News Review 9, 29-31.

Macrae J, Jaspers S, Duffield M, Bradbury M \& Johnson D (1997) Conflict, the continuum and chronic emergencies: a critical analysis of the scope for linking relief, rehabilitation and development planning in Sudan. Disasters 21, 140-151.

Mears C \& Young H (1998) Acceptability and Use of Cereal Based Foods in Refugee Camps. Oxfam Working Paper. Oxford: Oxfam.

Mennell S, Murcott A \& van Otterloo AH (1992) The Sociology of Food: Eating, Diet and Culture. London: Sage.

Muehlhoff E \& Herens M (1997) Household food security and nutrition in agricultural relief and rehabilitation programmes. Food, Nutrition and Agriculture 19, 4-12.

Patel M (1994) An examination of the 1990-91 famine in Sudan. Disasters 18, 313-331.

Payne L (1998) Food shortages and gender relations in Ikafe settlement Uganda. Gender and Development 6, 30-36.

Pratt B \& Boyden J (1985) The Field Directors' Handbook. Oxford: Oxfam, Oxford University Press.

Pratten D (1997) Local institutional development and relief in Ethiopia: A kire-based seed distribution programme in North Wollo. Disasters 21, 138-154.

Reed BA \& Habicht JP (1998) Sales of food aid as sign of distress not excess. Lancet 351, 128-130.

Seaman J (1987) The limits to the use of international aid as a means of securing improvement in food production and nutrition. Proceedings of the Nutrition Society 46, 267-272.

Seaman J (1993a) Aid programme for malnutrition and the role of the nutritionist. Proceedings of the Nutrition Society 53, $175-182$.

Seaman J (1993b) Comment. Nutritional Issues in Food Aid. Symposium Report Nutrition Policy Discussion Paper no. 12, pp. 91-92. Geneva: ACC/SCN.
Shapouri S \& Missiaen M (1995) Shortfalls in international food aid expected. Food Review 18, 44-50.

Shaw J \& Clay E (editors) (1993) Convergence and diversity evolution of food aid policies. In World Food Aid Experiences of Recipients and Donors, pp. 1-39. Rome, London and Portsmouth: World Food Programme with James Curry and Heinemann.

Shoham J (1992) Emergency feeding programmes. British Medical Journal 305, 596-597.

Short C (1998) Guardian 30 May issue, p. 22.

The Nutrition Society (1997) Register of Public Health Nutritionists: Philosophy and How to Apply. London: The Nutrition Society.

Toole M (1993) Protecting refugees' nutrition with food aid. Nutritional Issues in Food Aid. Symposium Report Nutrition Policy Discussion Paper no. 12. Geneva: ACC/SCN.

United Nations Children's Fund (1998) United Nations Children's Fund News in Brief. March issue. New York: UNICEF.

United Nations Development Programme (1997) Human Development 1996. New York: United Nations Development Programme.

Walker DJ (1996) Improving the efficiency and cost effectiveness of food aid grain delivery. Disasters 20, 133-143.

Waterlow JC (1987a) Discussion on famine: introductory remarks. Proceedings of the Nutrition Society 46, 259-261.

Waterlow JC (1987b) Discussion on famine: general discussion on famine. Proceedings of the Nutrition Society 46, 309-319.

Watson F (1998) Recipe for disaster. The Health Exchange 8-9 April issue.

Watson F \& Vespa J (1995) The impact of a reduced and uncertain food supply in 3 besieged cities of Bosnia-Hercegovina. Disasters 19, 216-234.

World Food Programme (1997) Nutritional Assessment Mission to the Democratic People's Republic of Korea. Pyongyang and Rome: World Food Programme in collaboration with FAO, UNICEF and Save the Children Fund, UK.

World Food Programme/International Food Aid Information System (1998) 1997 Food Aid Flows. The Food Aid Monitor Special Issue. Rome: World Food Programme.

World Health Organization (1994) From Disaster Management to Sustainable Development: How Public Sector Private Sector and Voluntary Organisations Can Work Together. World Conference on Natural Disaster Reduction. WHO/EHA/EPP Conf. 94.4. Geneva: WHO. 
https://doi.org/10.1017/S0029665199000476 Published online by Cambridge University Press 